\title{
Serotonergic hallucinogens differentially modify gamma and high frequency oscillations in the rat nucleus accumbens
}

\author{
Sailaja A. Goda • Joanna Piasecka • Maciej Olszewski • \\ Stefan Kasicki • Mark J. Hunt
}

Received: 23 August 2012 / Accepted: 11 February 2013 /Published online: 23 March 2013

(C) The Author(s) 2013. This article is published with open access at Springerlink.com

\begin{abstract}
Rationale The nucleus accumbens (NAc) is a site critical for the actions of many drugs of abuse. Psychoactive compounds, such as $\mathrm{N}$-methyl-D-aspartate receptor (NMDAR) antagonists, modify gamma (40-90) and high frequency oscillations (HFO, $130-180 \mathrm{~Hz}$ ) in local field potentials (LFPs) recorded in the NAc. Lysergic acid diethylamide (LSD) and 2,5-dimethoxy4-iodoamphetamine (DOI) are serotonergic hallucinogens and activation of $5 \mathrm{HT}_{2 \mathrm{~A}}$ receptors likely underlies their hallucinogenic effects. Whether these compounds can also modulate LFP oscillations in the NAc is unclear.

Objective This study aims to examine the effect of serotonergic hallucinogens on gamma and HFO recorded in the $\mathrm{NAc}$ and to test whether $5 \mathrm{HT}_{2 \mathrm{~A}}$ receptors mediate the effects observed.

Methods LFPs were recorded from the NAc of freely moving rats. Drugs were administered intraperitoneally.

Results LSD $(0.03-0.3 \mathrm{mg} / \mathrm{kg})$ and DOI $(0.5-2.0 \mathrm{mg} / \mathrm{kg})$ increased the power and reduced the frequency of HFO. In contrast, the hallucinogens produced a robust reduction in the power of low $(40-60 \mathrm{~Hz})$, but not high gamma oscillations (70$90 \mathrm{~Hz})$. MDL $11939(1.0 \mathrm{mg} / \mathrm{kg})$, a $5 \mathrm{HT}_{2 \mathrm{~A}}$ receptor antagonist, fully reversed the changes induced by DOI on HFO but only partially for the low gamma band. Equivalent increases in HFO power were observed after TCB-2 $\left(5 \mathrm{HT}_{2 \mathrm{~A}}\right.$ receptor agonist, $0.1-1.5 \mathrm{mg} / \mathrm{kg})$, but not $\mathrm{CP} 809101\left(5 \mathrm{H}_{2 \mathrm{C}}\right.$ receptor agonist, $0.1-3 \mathrm{mg} / \mathrm{kg}$ ). Notably, hallucinogen-induced increases in HFO
\end{abstract}

Electronic supplementary material The online version of this article (doi:10.1007/s00213-013-3057-1) contains supplementary material, which is available to authorized users.

S. A. Goda $(\bowtie) \cdot$ J. Piasecka $\cdot$ M. Olszewski $\cdot$ S. Kasicki $\cdot$

M. J. Hunt

Laboratory of the Limbic System, Nencki Institute of

Experimental Biology, 3 Pasteur Street,

02-093 Warsaw, Poland

e-mail: s.goda@nencki.gov.pl power were smaller than those produced by ketamine (25 mg/kg).

Conclusions Serotonergic hallucinogen-induced changes in HFO and gamma are mediated, at least in part, by stimulation of $5 \mathrm{HT}_{2 \mathrm{~A}}$ receptors. Comparison of the oscillatory changes produced by serotonergic hallucinogens and NMDAR antagonists are also discussed.

Keywords Accumbens · High frequency oscillations · Gamma $\cdot$ Rat $\cdot$ Serotonin receptor $\cdot$ Lysergic acid diethylamide $\cdot$ Hallucinogens $\cdot$ Local field potentials

\section{Introduction}

Lysergic acid diethylamide (LSD) and 2,5-dimethoxy-4iodoamphetamine (DOI) are potent hallucinogens known to produce changes in mood, thought, and sensory perception in humans. LSD is structurally classified as an indoleamine and is a relatively nonselective agonist active at serotonergic receptors as well as on other receptor systems (Halberstadt and Geyer 2011; Marona-Lewicka et al. 2009; Teitler et al. 1990). DOI is a phenethylamine that displays high affinity for $5 \mathrm{HT}_{2 \mathrm{~A} / 2 \mathrm{C}}$ receptor subtypes (Appel et al. 1990; Johnson et al. 1987; Krebs-Thomson et al. 1998). Despite differences in chemical structure and pharmacology, these compounds produce relatively similar behavioural effects in humans and rats, much of which appears to be associated with activation of the 5- $\mathrm{HT}_{2 \mathrm{~A}}$ receptor subtype; for reviews, see Aghajanian and Marek (1999), Halberstadt and Geyer (2011), Nichols (2004), and Passie et al. (2008).

The nucleus accumbens (NAc) is widely considered to function as a limbic-motor interface, receiving projections from the prefrontal cortex, hippocampus, and amygdala, along with a dense dopaminergic input from the ventral tegmental area (Finch 1996; O’Donnell and Grace 1995; 
Oades and Halliday 1987). Altered functioning of these limbic regions may contribute to the effects produced by psychoactive compounds (Jentsch and Roth 1999; Vollenweider and Geyer 2001). In a drug discrimination study, local infusion of LSD to the NAc produced a cueing effect equivalent to that of systemic administration (Nielsen and Scheel-Kruger 1986) suggesting that this structure may directly participate in some of the core effects of hallucinogenic compounds. Accumbal neurons, express $5 \mathrm{HT}_{2 \mathrm{~A}}$ and $5 \mathrm{HT}_{2 \mathrm{C}}$ receptors (McKenna et al. 1989; Pazos et al. 1985; Pazos and Palacios 1985) and an in situ hybridization study on rats injected with LSD showed increased $c$-fos expression in the NAc (Erdtmann-Vourliotis et al. 1999). In vitro, application of 5HT can depolarise accumbal neurons (North and Uchimura 1989) and radiolabelled $\mathrm{I}^{125}$ DOI can bind to $5 \mathrm{HT}_{2}$ receptors in the NAc (Appel et al. 1990). Thus, the NAc may be an important region in mediating the effects of serotonergic hallucinogens.

Local field potentials (LFPs) primarily reflect the sum of currents arising predominantly from synchronised synaptic input. Many drugs of abuse, such as ketamine, tetrahydrocannabinol, and amphetamine, have been shown to influence oscillations in different brain areas (Berke 2009; Hunt et al. 2011; Kargieman et al. 2007; Ma and Leung 2000; Pinault 2008; Robbe et al. 2006). Serotonergic hallucinogens produce a general decrease in the power of LFP oscillations in several brain areas of freely moving rats (with exception to alpha where increases are observed; Dimpfel et al. 1989). More recent studies have demonstrated a decrease in the power of cortical delta oscillations in anesthetised rats (Celada et al. 2008) and a more generalised decrease in frequency bands up to $50 \mathrm{~Hz}$ (Palenicek et al. 2012). However, to date, the effects of serotonergic hallucinogens on LFP oscillations recorded from the rat NAc are largely unknown.

In the NAc, gamma can be divided into two frequency bands, low gamma $(40-60 \mathrm{~Hz})$ and high gamma (70-90 Hz; for review see, van der Meer et al. (2010)). Systemic injection of D-amphetamine and methamphetamine reduce the power of low gamma but increase high gamma power in the NAc of freely moving rats (Berke 2009; Morra et al. 2012). Frequencies above the gamma range, known as high-frequency oscillations $(130-180 \mathrm{~Hz})$, also occur in the NAc of freely moving rats. $N$-methyl-D-aspartate receptor (NMDAR) antagonists, such as ketamine, substantially increase the power of high-frequency oscillations (HFO) in this region. Much smaller increases in HFO power are produced by the psychostimulant D-amphetamine (Hunt et al. 2006). Considering that distinct classes of psychoactive compounds can modify LFP oscillations in the NAc, we examined the effect of serotonergic hallucinogens on gamma and HFO in the NAc of freely moving rats.

\section{Methods}

\section{Surgery}

Thirty-three male Wistar rats $(250-350 \mathrm{~g})$ in total were used in this study. Rats were anaesthetized with isoflurane and implanted unilaterally with twisted stainless steel electrodes (110 $\mu \mathrm{m}$, Science Products, Germany) insulated except at the tip targeted to NAc according to the coordinates of the stereotaxic atlas (Paxinos and Watson 1988) [AP $(+1.6 \mathrm{~mm})$ and LM $(+1.2 \mathrm{~mm})$ with respect to bregma, DV $(-7.1 \mathrm{~mm})$, with respect to cortical surface]. A silver wire connected to a skull screw posterior to the bregma was used as the ground/reference. The locations of the recording electrodes were determined on $40 \mu \mathrm{m}$ Cresyl violet stained sections post mortem.

Experimental procedure

One week after surgery, the animals were handled for approximately $30 \mathrm{~min}$ per day, for 2 days. Following this, LFPs were recorded to check the signal quality, habituate the animals to the experimental chamber, and also to the process of connecting/disconnecting to the recording cable. Experiments were performed from $8 \mathrm{AM}$ to $7 \mathrm{PM}$. LFPs were recorded using a JFET preamplifier at the head stage, the signals were relayed through a 25 -channel commutator (Crist Instruments, USA), amplified $\times 1,000$, filtered $0.1-$ $1000 \mathrm{~Hz}$ (A-M Systems, USA), digitised $4 \mathrm{kHz}$ (Micro1401, CED, Cambridge, UK) and stored on a PC for offline analysis. The animals were grouped according to the experimental destinations described in Table 1 . Locomotor activity was assessed by beam-breaks (Columbus Instruments, USA). All experiments were performed according to a Latin square design, whereby every animal received each dose of the drug in a pseudorandomised order. The drug washout between consecutive experiments was at least 3 days. All experiments were conducted in accordance with the European Guidelines on the Care and Use of Laboratory Animals (86/609/EEC) and approved by a local ethics committee. All efforts were made to minimise the suffering of the animal and to reduce the number of animals used.

\section{Drug treatments}

Rats were injected intraperitoneally (i.p.) with different doses of the drug/vehicle as mentioned in Table 1. At least 3 days elapsed between all injections of drug or vehicle. Rats were baselined for 20 min prior to injection and then recorded for at least $60 \mathrm{~min}$ thereafter, with exception to group 3. At the end of the main experiment, these rats received injection of ketamine (i.p). In group 3, every rat 
Table 1 Rat groups and their respective drug treatment regimen for the main and auxiliary experiments

\begin{tabular}{|c|c|c|}
\hline $\begin{array}{l}\text { Rat groups } \\
\text { (no. of animals) }\end{array}$ & Drug treatment (i.p) - main experiment & $\begin{array}{l}\text { Treatment after all main } \\
\text { experiments (i.p.) }\end{array}$ \\
\hline Group $1(N=7)$ & $\operatorname{LSD}(0.03,0.1$, and $0.3 \mathrm{mg} / \mathrm{kg}$ ) or vehicle (a few drops of acetic acid in saline) & Ketamine $(25 \mathrm{mg} / \mathrm{kg})$ \\
\hline Group $2(N=6)$ & DOI $(0.5,1$, and $2 \mathrm{mg} / \mathrm{kg})$ or vehicle (saline) & Ketamine $(25 \mathrm{mg} / \mathrm{kg})$ \\
\hline Group $3(N=8)$ & $\begin{array}{l}\text { DOI }(2 \mathrm{mg} / \mathrm{kg}) / \mathrm{saline} \text { followed } 30 \mathrm{~min} \text { later by injection of MDL } 11939 \\
(1.0 \mathrm{mg} / \mathrm{kg}) / \mathrm{vehicle}(\mathrm{DMSO})\end{array}$ & $\begin{array}{l}\text { DOI }(2 \mathrm{mg} / \mathrm{kg}) \text { followed by } \\
\text { SB } 242084(1 \mathrm{mg} / \mathrm{kg})(N=4)\end{array}$ \\
\hline Group $4(N=6)$ & TCB-2 $(0.1,0.5$, and $1.5 \mathrm{mg} / \mathrm{kg})$ or vehicle (distilled water) & Ketamine $(25 \mathrm{mg} / \mathrm{kg})$ \\
\hline Group $5(N=6)$ & CP $809101(0.1,1$, and $3 \mathrm{mg} / \mathrm{kg})$ or vehicle (10\% DMSO in distilled water) & Ketamine $(25 \mathrm{mg} / \mathrm{kg})$ \\
\hline
\end{tabular}

received each of the four combinations of drugs DOI-MDL 11939, DOI-vehicle, saline-MDL 11939, and saline-vehicle. Additionally, after this main experiment, four rats from this group were injected with DOI followed 30 min later by injection of SB 242084. LSD and ketamine were purchased from Sigma-Aldrich (Poznan, Poland), DOI hydrochloride, MDL 11939, SB 242084, TCB-2 and CP 809101 hydrochloride were purchased from Tocris Bioscience (UK).

\section{Data processing}

The raw LFPs were cleaned to remove movement large artefacts and then were analysed using Spike2 software. Total power of frequency bands-HFO (typically $130-180 \mathrm{~Hz}$, for TCB-2 and CP 809101 studies 110-180 Hz was used) and gamma (low 40-60 Hz and high 70-90 Hz) — were analysed in $60 \mathrm{~s}$ data bins using FFT's of 4096 points (Spike2). HFO events were extracted by filtering the raw signal with a digital band pass filter at $130-180 \mathrm{~Hz}$ and oscillatory episodes greater than 6SD were marked by events, as described previously (Hunt et al. 2008). Inter-event intervals were calculated as an index of HFO frequency.

\section{Statistical analysis}

Data were expressed as percentage of baseline values (percent change) and analysed using either, repeated-measures two-way analysis of variance (ANOVA) or one-way ANOVA. Bonferroni post hoc tests were used to find significant differences between doses/drugs. Values were expressed as mean \pm SEM and were considered to be significant if $p<0.05$.

\section{Results}

Changes in the rat behaviour after injection of serotonergic hallucinogens

Intraperitoneal injection of LSD $(0.03,0.1$, and $0.3 \mathrm{mg} / \mathrm{kg})$ or DOI $(0.5,1$, and $2 \mathrm{mg} / \mathrm{kg})$ produced similar characteristics of changes in behaviour including, head twitches, wet-dog shakes, and altered posture with the rat often remaining in one corner of the recording chamber and lying flat. For both drugs, these effects were more pronounced at higher doses and typically lasted for the duration of the experiment.

Motor activity was evaluated by analysing the total number of beam breaks in $60 \mathrm{~s}$ bins $-20 \mathrm{~min}$ at baseline and $60 \mathrm{~min}$ after injection. Two-way ANOVA with time as the repeatedmeasure showed a significant effect of LSD on beam-breaks (dose $\times$ time $F_{234,1872}=1.38, p=0.0003$ ). Bonferroni post hoc test showed a significant reduction in movement for all doses of LSD versus vehicle, but this was significant for only one time point for all the doses $(p<0.01)$. There were no other significant differences. For the DOI group, we did not observe any significant dose $\times$ time interaction $\left(F_{234,1560}=0.670\right.$, $p=0.999)$. At the end of the LSD/DOI studies, all rats received an injection of $25 \mathrm{mg} / \mathrm{kg}$ ketamine which produced an immediate increase in the beam breaks lasting around $10 \mathrm{~min}$ (LSD, $F_{312,2340}=3.20, p<0.0001$; DOI, $\left.F_{312,1950}=1.61, p<0.0001\right)$. Bonferroni post hoc test revealed a significant increase in beam breaks for ketamine versus all doses of LSD/DOI and their vehicle $(p<0.001)$.

Serotonergic hallucinogens increase the power of high-frequency oscillations in the LFPs of nucleus accumbens

LFPs were recorded before and at least $1 \mathrm{~h}$ after i.p. injection of LSD $(0.03,0.1$, and $0.3 \mathrm{mg} / \mathrm{kg})$, DOI $(0.5,1$, and $2 \mathrm{mg} / \mathrm{kg})$ or vehicle. Systemic administration of both LSD and DOI increased the power of HFO (130-180 Hz) but decreased the power of the gamma band. Representative time courses of these LFP changes, expressed as spectrograms are shown in Figs. 1a and 2a. Power spectra $(10 \mathrm{~min})$ before and after injection of LSD and DOI are shown in Figs. $1 b$ and $2 b$.

Time courses showing the mean power of HFO (expressed as percent change) for the LSD and DOI studies are shown in Figs. 1c and 2c, respectively. For both LSD and DOI groups, repeated-measures two-way ANOVA revealed a significant effect of dose (LSD, $F_{3,24}=3.9, p=0.0212$; DOI group, $F_{3,20}=3.77, p=0.0271$ ), time (LSD group, $F_{79,1896}=10.15$, 
LSD

a
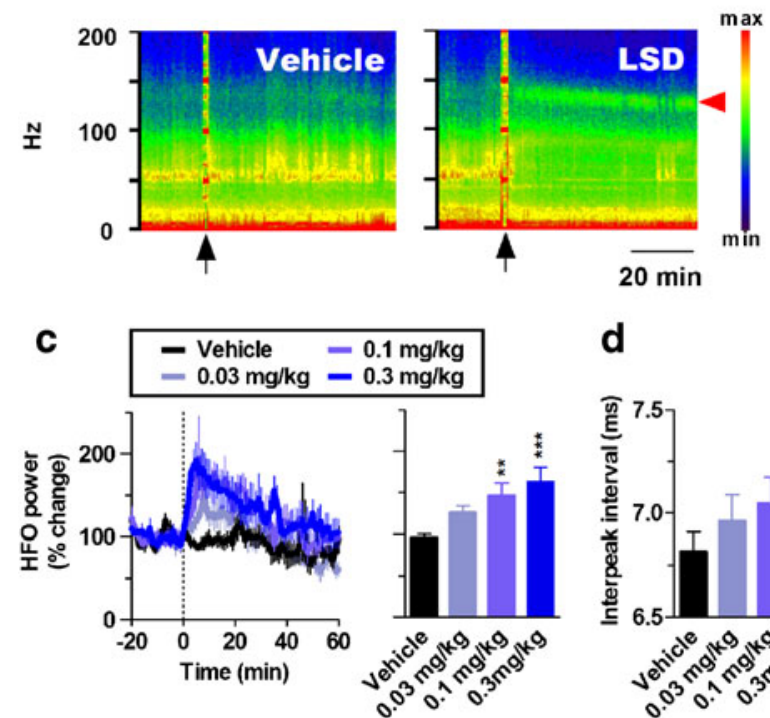

e

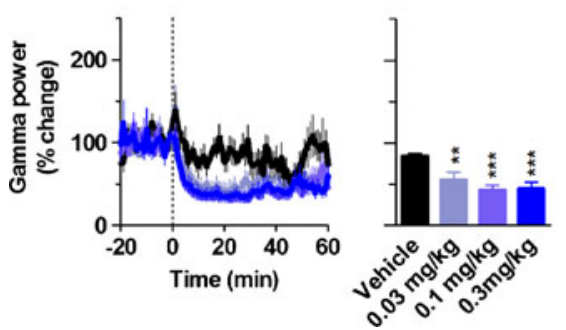

d
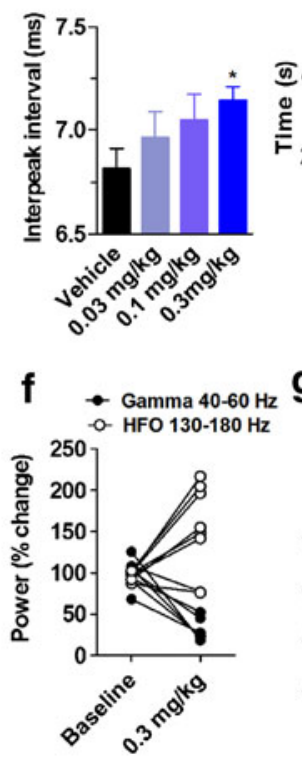

b

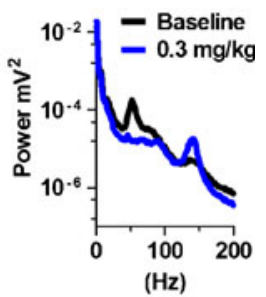

g

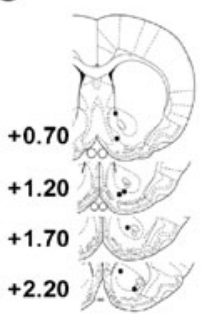

Fig. 1 LSD modulates the power of HFO $(130-180 \mathrm{~Hz})$ and low gamma $(40-60 \mathrm{~Hz})$ in the NAc of freely moving rats. a Representative spectrograms showing changes in the power of HFO and gamma power across time for vehicle and LSD $0.3 \mathrm{mg} / \mathrm{kg}$. Black arrows indicate time of injection and the red arrow head indicates the HFO band. Colour scales are logarithmic and are the same in both examples. b Power spectra (10-min average) from an example rat at baseline and after injection of $0.3 \mathrm{mg} / \mathrm{kg}$ LSD. c Time courses showing the effect of LSD $(0.03,0.1$, and $0.3 \mathrm{mg} / \mathrm{kg})$ on the power of HFO. Broken line indicates time of injection. Mean powers of HFO (20-min average) are shown alongside. d The effects of LSD on interpeak interval of HFO events are shown for the first 20 min post-injection. Raster plot shows the distribution of HFO events across time for LSD $0.3 \mathrm{mg} / \mathrm{kg}$. Injection is indicated by the gap. Note the increased inter-event interval and number of HFO events post-injection. e Time courses showing the effect of LSD $(0.03,0.1$, and $0.3 \mathrm{mg} / \mathrm{kg})$ on the power gamma. Mean powers of gamma (60-min average) post injection are shown alongside. f Power of HFO (clear circles) and gamma (filled circles) for individual rats $10 \mathrm{~min}$ before and after injection of $0.3 \mathrm{mg} / \mathrm{kg}$ of LSD. All animals (except one rat) showed a clear increase in the power of HFO and decrease in the power of gamma when compared to the baseline activity. g Placement of electrodes, $N=7$ rats are indicated by the black dots. Values expressed as mean \pm SEM, $* p<0.05$, $* * p<0.01, * * * p<0.001$ with respect to vehicle $p<0.0001$; DOI group, $\left.F_{78,1560}=5.24, p<0.0001\right)$ and interaction (LSD group, $F_{237,1896}=1.84, p<0.0001$; DOI group, $\left.F_{234,1560}=2.53, p<0.0001\right)$. For the LSD group, Bonferroni post hoc tests revealed significant increases in the power of HFO for 0.1 and $0.3 \mathrm{mg} / \mathrm{kg}$ doses compared to vehicle ( $p<0.001$, for both), but no difference for $0.03 \mathrm{mg} / \mathrm{kg}$, the lowest dose tested. For the DOI group, Bonferroni post hoc tests revealed significant differences for $1 \mathrm{mg} / \mathrm{kg}(p<0.05)$ and $2 \mathrm{mg} / \mathrm{kg}$ doses $(p<0.001)$, compared to vehicle, but no difference for $0.5 \mathrm{mg} / \mathrm{kg}$, the lowest dose tested. The dose of $0.5 \mathrm{mg} / \mathrm{kg}$ significantly differed from the $2 \mathrm{mg} / \mathrm{kg}$ dose $(p<0.001)$.
Additionally, we analysed data for the first 20 min after administration of the drug as the time courses of HFO power showed major effects that occurred during this time. Analysis confirmed that both LSD and DOI produced a significant increase in the power of HFO. Repeated-measures one-way ANOVA revealed a significant effect for both LSD and DOI groups (LSD, $F_{3,18}=9.39, p<0.0006$; DOI, $F_{3,15}=12.12$, $p<0.0003$, shown alongside the time courses in Figs. $1 \mathrm{c}$ and $2 c)$. Bonferroni post hoc test revealed, significant increases in the power of HFO for $0.1 \mathrm{mg} / \mathrm{kg}(p<0.01)$ dose and $0.3 \mathrm{mg} / \mathrm{kg}$ $(p<0.001)$ of LSD and for $2 \mathrm{mg} / \mathrm{kg}(p<0.001)$ dose of DOI group in comparison to the vehicle. 


\section{DOI}

a
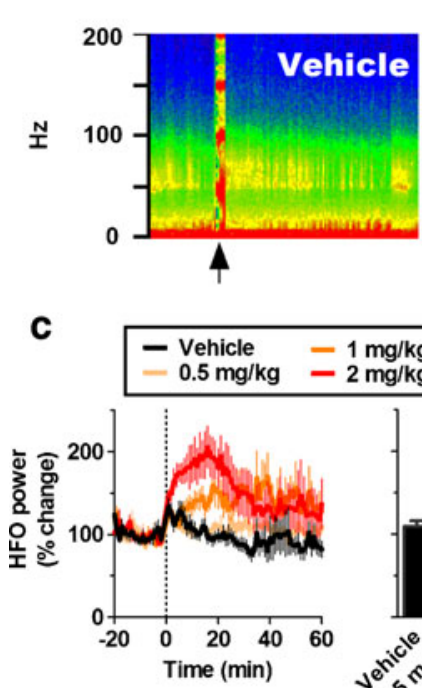

$-1 \mathrm{mg} / \mathrm{kg}$ $2 \mathrm{mg} / \mathrm{kg}$

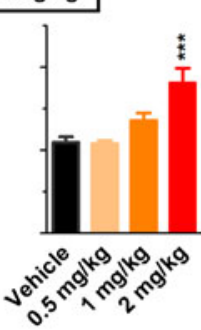

e
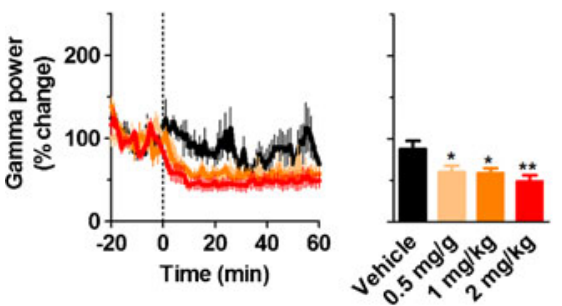

Fig. 2 DOI modulates the power of HFO $(130-180 \mathrm{~Hz})$ and gamma $(40-60 \mathrm{~Hz})$ in the NAc of freely moving rats. a Representative spectrograms showing changes in the power of HFO and gamma across time for vehicle and DOI $2 \mathrm{mg} / \mathrm{kg}$. Black arrows indicate time of injection and the red arrow head points to the HFO band. Colour scales are logarithmic and are the same in both examples. b Power spectra (10min average) from an example rat at baseline and after injection of $2 \mathrm{mg} / \mathrm{kg}$ DOI. c Time courses showing the effect of DOI $(0.5,1$, and $2 \mathrm{mg} / \mathrm{kg}$ ) on the power of HFO. Broken line indicates time of injection. Mean powers of HFO (20-min average) after injection are shown alongside. d Effect of DOI on interpeak interval of HFO events are

To determine whether serotonergic hallucinogens influence the frequency of HFO, the raw LFPs were digitally 130$180 \mathrm{~Hz}$ bandpass filtered and the peaks of oscillations ( $>6$ SD baseline) were marked. The interpeak intervals for the first $20 \mathrm{~min}$ after injection of drugs or vehicle were analysed (Figs. 1d and 2d). Repeated-measures one-way ANOVA revealed a significant effect of drug on the inter-peak interval (LSD, $F_{3,18}=3.658, p=0.0322$; DOI, $F_{3,15}=19.79, p<0.0001$ ). In both groups, Bonferroni post hoc test revealed an increase in the interpeak interval, with respect to vehicle, that was significant for the highest dose of LSD $(p<0.05)$ and for all doses of DOI (at least, $p<0.05$ ). The raster plot shows individual peaks of HFO ( $>6 \mathrm{SD})$ and a gradual increase in the inter-event interval indicative of reduced frequency (Figs. 1d and 2d). b

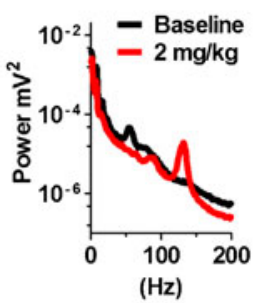

d
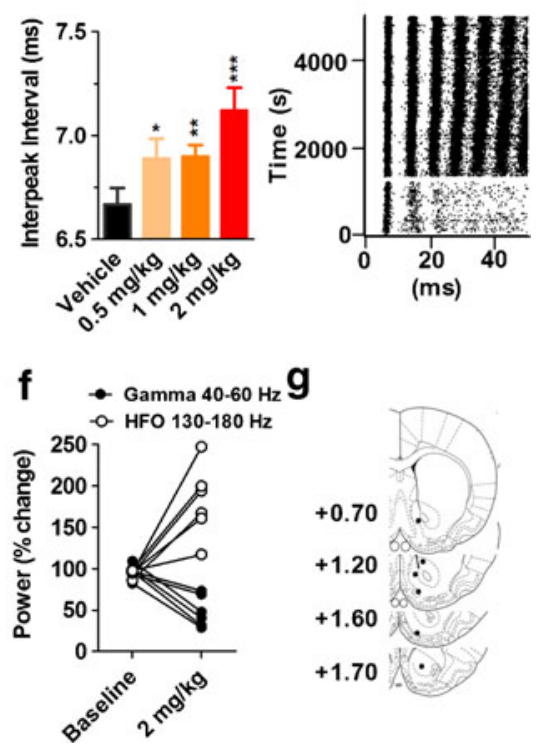

shown for the first 20 min post-injection. Raster plot shows the distribution of HFO events across time for DOI $2 \mathrm{mg} / \mathrm{kg}$. e Time courses showing the effect of DOI on the power of gamma in NAc. Mean powers of gamma (60-min average) after injection are shown alongside. f Power of HFO (clear circles) and gamma (filled circles) for individual rats $10 \mathrm{~min}$ before and after injection of $2 \mathrm{mg} / \mathrm{kg}$ DOI. All animals showed a clear increase in the power of HFO and decrease in the power of gamma when compared to the baseline activity. $g$ Placement of electrodes, $N=6$ rats are indicated by the black dots. Values expressed as mean \pm SEM, ${ }^{*} p<0.05,{ }^{*} p<0.01, * * * p<0.001$ with respect to vehicle

Serotonergic hallucinogens reduce the power of gamma oscillations in the LFPs of nucleus accumbens

Low gamma $(40-60 \mathrm{~Hz})$ This band was clearly visible in the baseline power spectra of most rats used in our study and corresponds with the frequency band that has been termed low gamma or gamma-50 in the NAc (Berke et al. 2004; Berke 2009; Kalenscher et al. 2010). Time courses of the total power of low gamma at baseline and after injection of LSD and DOI are shown in Figs. 1e and 2e. For both LSD and DOI groups, repeated-measures two-way ANOVA revealed a significant effect of dose (LSD group, $F_{3,24}=7.83, p=0.0008$; DOI group, $F_{3,20}=4.46, p=0.015$ ), time (LSD group, $F_{79,1896}=16.82, p<0.0001 ;$ DOI group, $F_{78,1560}=17.04$, 
$p<0.0001$ ) and interaction (LSD group, $F_{237,1896}=1.38$, $p=0.0002$; DOI group, $F_{234,1560}=1.53, p<0.0001$ ). For the LSD group, Bonferroni post hoc tests revealed a significant decrease in the total power of low gamma for 0.1 and $0.3 \mathrm{mg} / \mathrm{kg}$ doses ( $p<0.01$ and $p<0.05$, respectively) compared to vehicle. For the DOI group, reductions in low gamma power were found for 1 and $2 \mathrm{mg} / \mathrm{kg}$ doses $(p<0.05$ and $p<0.01$, respectively) compared to the vehicle. Repeated-measures one-way ANOVA for the entire 60-min post-injection period revealed a significant effect of dose $\times$ time interaction (LSD, $F_{3,18}=16.55$, $p<0.0001$; DOI, $F_{3,15}=7.078, p=0.0035$, shown alongside Figs. 1e and 2e). Bonferroni post hoc revealed significant reductions in the power of low gamma for all doses of LSD $(0.03 \mathrm{mg} / \mathrm{kg}, p<0.01,0.1$ and $0.3 \mathrm{mg} / \mathrm{kg}, p<0.001)$ and DOI $(0.5$ and $1 \mathrm{mg} / \mathrm{kg}, p<0.05$ and $2 \mathrm{mg} / \mathrm{kg}, p<0.01)$ tested when compared to vehicle.

High gamma (70-90 Hz) After injection of the highest doses of LSD and DOI, a band in the high gamma range could be discerned in the spectrograms. However, repeatedmeasures two-way ANOVA did not reveal a significant effect of the dose (LSD group, $F_{3,24}=0.79, p<0.5119$; DOI group, $F_{3,20}=0.86, p=0.479$ ) and interaction (LSD group, $F_{237,1896}=0.98, p=0.5516$; DOI group, $F_{234,1560}=0.99$, $p=0.5367$ ). See also the example spectrograms (shown in Figs. 1 and 2) demonstrating the change in low and high gamma power distribution of across time after LSD and DOI injection. When the power of high gamma was expressed as a percentage of the whole gamma range, we found a significant increase in the proportion of high gamma for the DOI group (dose $\times$ time, $F_{237,1580}=1.48, p<0.0001$ ) but not for the LSD group (dose $\times$ time, $F_{237,1896}=1,13, p=0.105$; Electronic supplementary material (ESM) Fig. 1).

Blockade of $5 \mathrm{HT}_{2 \mathrm{~A}}$ receptors reverse the increase in HFO power produced by DOI

In a separate study, $30 \mathrm{~min}$ after injection of $2 \mathrm{mg} / \mathrm{kg}$ DOI, the animals received an i.p injection of the potent $5 \mathrm{HT}_{2 \mathrm{~A}}$ receptor antagonist $1 \mathrm{mg} / \mathrm{kg}$ MDL 11939 or vehicle. Example spectrograms are shown in Fig. 3a and power spectra in Fig. 3b. Time courses showing the effect of MDL 11939/vehicle after DOI pretreatment on the total power of HFO are shown in Fig. 3c. Repeated-measures two-way ANOVA revealed a significant effect of the drug $\left(F_{1,14}=7.45, p=0.016\right)$, time $\left(F_{107,1498}=24.54, p<0.0001\right)$ and interaction $\left(F_{107,1498}=10.12, p<0.0001\right)$. Bonferroni post hoc tests revealed a significant and sustained reduction in the power of HFO for rats injected with MDL 11939 compared to vehicle $(p<0.001)$. In the saline-pretreated rats, there was no significant effect of MDL 11939 injection on the power of HFO (ESM Fig. 2). After the main experiment, four out of eight rats were injected with $1 \mathrm{mg} / \mathrm{kg}$ SB 242084 $30 \mathrm{~min}$ after injection of $2 \mathrm{mg} / \mathrm{kg}$ of DOI. Time courses showing the effect of SB 242084 on DOI-induced increases in HFO power are shown in Fig. 3f. Although a trend for a reduction in HFO power was observed, repeated-measures two-way ANOVA did not reveal any significant effect of drug $\left(F_{1,6}=0.9, p=0.378\right)$ or drug $\times$ time interaction $\left(F_{102,612}=1.26, p=0.0525\right)$.

It is interesting to note that reductions in the power of HFO after MDL 11939 administration in the DOI pretreated group was immediate and even dropped below the baseline activity for some time but then recovered back to the baseline activity (see Fig. 3a and c). Due to the attenuation of HFO power after injection of MDL 11939, it was not possible to accurately determine the power of dominant frequency in the power spectra or band-pass filtered signals. However, on occasions when bouts of HFO were present in the LFP the frequency did not appear markedly different to the baseline values.

We also analysed the effect of MDL 11939 administration on DOI-induced reductions in low gamma power $(40-60 \mathrm{~Hz}$; Fig. 3d). Repeated-measures two-way ANOVA revealed a significant effect of the time $\left(F_{107,1498}=7.59, p<0.0001\right)$ and interaction $\left(F_{107,1498}=2.41, p<0.0001\right)$ but not for the drug $\left(F_{1,14}=0.64, p=0.438\right)$ on the total power of low gamma. Bonferroni post hoc test revealed a short lasting significant increase in the total power of low gamma after MDL 11939 administration $(p<0.05, p<001, p<0.0001)$ compared to the vehicle group. In four rats, we also examined the effect of SB 242084 on the gamma changes induced by DOI and compared this to vehicle values. Time courses showing the effect of SB 242084 /vehicle on the reduction in low gamma $(40-60 \mathrm{~Hz})$ induced by DOI are shown in Fig. 3g. Repeatedmeasures two-way ANOVA did not reveal any significant effect of drug $\left(F_{1,6}=0.12, p=0.743\right)$ or drug $\times$ time interaction $\left(F_{102,612}=0.64, p=0.997\right)$.

Activation of $5 \mathrm{HT}_{2 \mathrm{~A}}$ receptors modulate the power and frequency of $\mathrm{HFO}$ more powerfully than $5 \mathrm{HT}_{2 \mathrm{C}}$ receptors

We performed an additional study using selective agonists at $5 \mathrm{HT}_{2 \mathrm{~A}}$ receptors, TCB- $2(0.1,0.5$, and $1.5 \mathrm{mg} / \mathrm{kg})$ and $5 \mathrm{HT}_{2 \mathrm{C}}$ receptors, CP $809101(0.1,1.0$, and $3 \mathrm{mg} / \mathrm{kg}) .5 \mathrm{HT}_{2 \mathrm{~A}}$ receptor activation, at the highest dose, led to a reduction in the frequency of HFO in four out of six rats (Fig. 4c). Therefore, the range of HFO power was evaluated over a broader range 110-180 Hz. Time courses showing the effect of TCB-2 and CP 809101 on the total power of HFO are shown in Fig. 4a and b. Repeated-measures two-way ANOVA revealed a significant effect of dose $\left(F_{3,20}=7.69\right.$, $p=0.0013)$, time $\left(F_{75,1500}=9.12, p<0.0001\right)$ and interaction $\left(F_{225,1500}=4.90, p<0.0001\right)$ for TCB-2. Bonferroni post hoc 

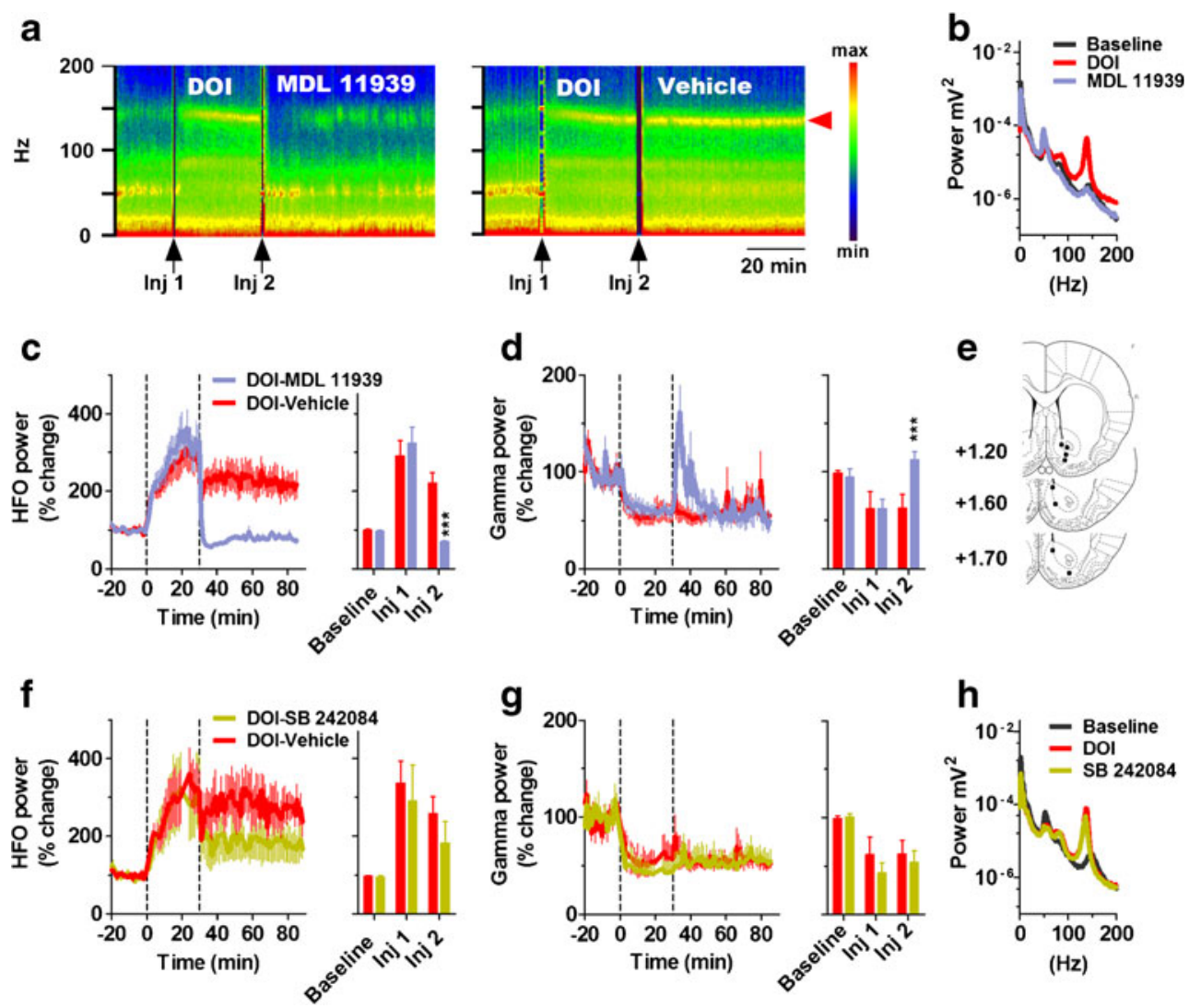

Fig. 3 Effect of antagonists at $5 \mathrm{HT}_{2 \mathrm{~A}}$ (MDL 11939) and $5 \mathrm{HT}_{2 \mathrm{C}}$ receptors (SB 242084) on altered oscillations induced by DOI. a Examples of spectrograms showing changes in the HFO and gamma power across time for DOI-MDL 11939 and DOI-vehicle group. Black arrows indicate injection times (Inj) and the red arrow head points to the HFO band. Colour scales are logarithmic and are the same in both examples. b Power spectra (10 min average) from an example rat at baseline, after injection of $2 \mathrm{mg} / \mathrm{kg}$ DOI and in the presence of $1 \mathrm{mg} / \mathrm{kg}$ of MDL 11939. c, d Time courses showing the effect of MDL 11939/vehicle on DOI-induced changes in HFO (130-180 Hz) and gamma power (40$60 \mathrm{~Hz}$ ), respectively. Mean power of HFO and gamma prior to and after injection of antagonist (10-min average) are shown alongside. f, $g$ Time courses showing the effect of SB 242084/vehicle $(N=4)$ on DOI-induced changes in HFO $(130-180 \mathrm{~Hz})$ and gamma power $(40$ $60 \mathrm{~Hz}$ ), respectively. Mean power of HFO and gamma prior to and after injection of antagonists (10-min average) are shown alongside. h Power spectra (10 min average) from an example rat at baseline, after injection of $2 \mathrm{mg} / \mathrm{kg}$ DOI and in the presence of $1 \mathrm{mg} / \mathrm{kg}$ SB 242084. Broken lines indicate times of injection. e Placement of electrodes for all the rats, $N=8$ are indicated by the black dots. Values expressed as mean \pm SEM, ${ }^{* * *} p<0.001$ with respect to vehicle test revealed a significant increase for the $1.5 \mathrm{mg} / \mathrm{kg}$ dose compared to vehicle $(p<0.001)$ and the other doses; $0.1 \mathrm{mg} / \mathrm{kg}$ $(p<0.001)$ and $0.5 \mathrm{mg} / \mathrm{kg}(p<0.01)$. No other differences were found. Repeated-measures two-way ANOVA for HFO power in the CP 809101 experiment revealed an effect of dose $\left(F_{3,20}=6.87, p=0.0023\right)$, time $\left(F_{73,1460}=9.31, p<0.0001\right)$, and interaction $\left(F_{219,1460}=1.69, p<0.0001\right)$. Bonferroni post hoc test revealed a small but significant increase for the highest dose of CP 809101 compared to vehicle $(p<0.001)$ and between $0.1 \mathrm{mg} / \mathrm{kg}(p<0.001)$ and $1 \mathrm{mg} / \mathrm{kg}$ doses $(p<0.05)$; in both cases, this was significant for only one time point). No other differences were found.

With respect to low gamma power, time-courses showing the effect of TCB-2 and CP 809101 on the total power of gamma are shown in Fig. 4d and e. Repeated-measures twoway ANOVA of the TCB-2 group revealed a significant effect of the dose $\left(F_{3,20}=3.06, p=0.0519\right)$ and time $\left(F_{75,1500}=19.10\right.$, $p<0.0001)$ but not interaction $\left(F_{225,1500}=0.96, p=0.6526\right)$. Bonferroni post hoc test did not reveal any significant differences in the power of low gamma when compared to vehicle. For the CP 809101 group, no significant drug effects or interactions were found for the dose $\left(F_{3,20}=0.97, p=0.4255\right)$ and interaction $\left(F_{219,1460}=1.10, p=0.1717\right)$.

Comparison of serotonergic hallucinogens and ketamine-induced changes in HFO and low gamma in the NAc

At the end of the LSD and DOI, studies the rats received an i.p. injection of $25 \mathrm{mg} / \mathrm{kg}$ ketamine (Fig. 5). Consistent with our previous findings, ketamine provoked a large increase in the power of HFO (Hunt et al. 2006, 2008). In one rat from 

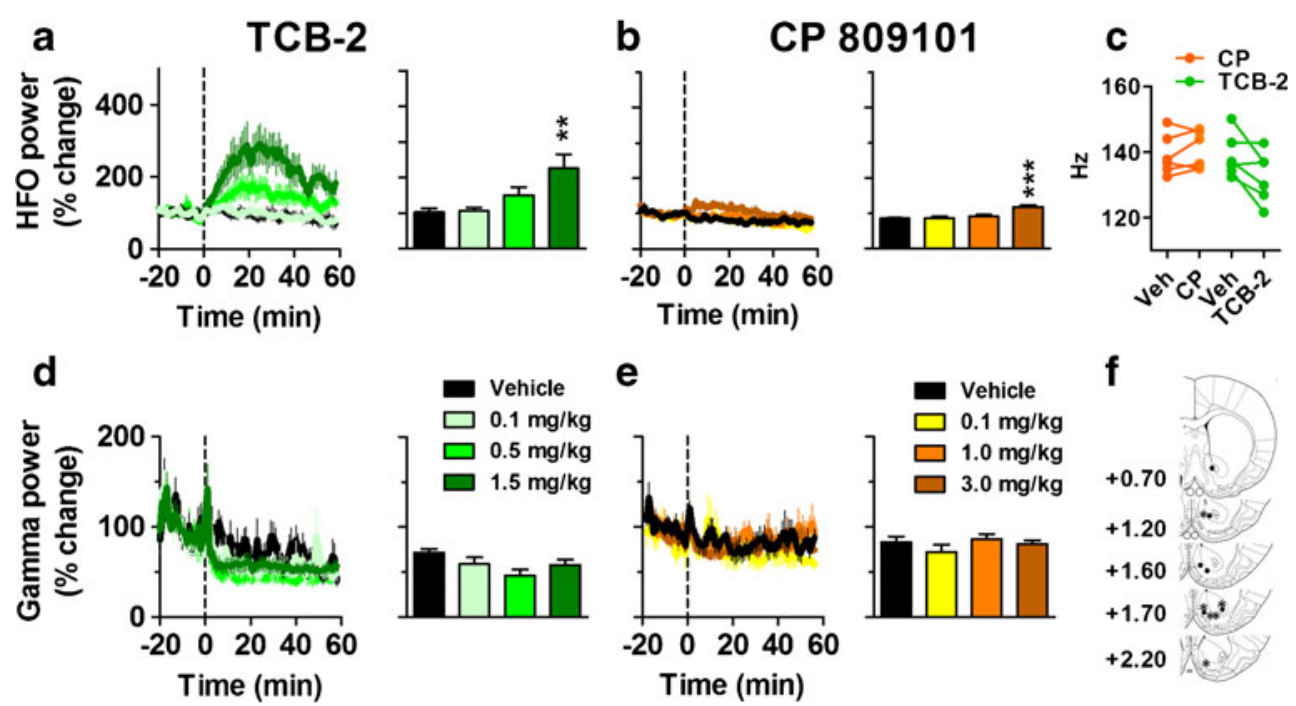

Fig. 4 Stimulation of $5 \mathrm{HT}_{2 \mathrm{~A}}$ (TCB-2), rather than $5 \mathrm{HT}_{2 \mathrm{C}}$ receptors (CP 809101), increase the power of HFO (110-180 Hz) in the NAc of freely moving rats. a, b Time courses showing the effect of TCB-2 $(0.1,0.5$, and $1.5 \mathrm{mg} / \mathrm{kg})$ and CP $809101(0.1,1$, and $3 \mathrm{mg} / \mathrm{kg})$ on HFO power. Mean powers of HFO (20-min average) after injection are shown alongside. c Individual plots showing the dominant frequency within the HFO band after injection for the highest dose of TCB-2 (green circles) or

CP 809101 (orange circles) compared to vehicle (Veh). d, e Time courses showing the effect of TCB-2 and CP 809101 on gamma power. Mean powers of gamma (60-min average) post-injection are shown alongside. Broken lines indicate time of injection. $\mathbf{f}$ Placement of electrodes for all the rats, $N=6$ for TCB- 2 group are indicated by black asterisks and $N=6$ for CP 809101 group are indicated by the black dots. Values expressed as mean \pm SEM, ${ }^{* *} p<0.01,{ }^{* * *} p<0.001$ with respect to vehicle

Fig. 5 Comparison of injection of ketamine and serotonergic hallucinogens on the power of HFO (130-180 Hz) and low gamma $(40-60 \mathrm{~Hz})$ in the NAc. a-d Time courses showing, changes in the total power of HFO and low gamma for all doses of LSD, DOI and $25 \mathrm{mg} /$ $\mathrm{kg}$ ketamine (data for LSD and DOI are taken from Figs. 1 and 2). Broken lines indicate time of injection. Note the immediate robust increase in the power of HFO lasting for $\sim 10$ min after injection of ketamine
LSD

a

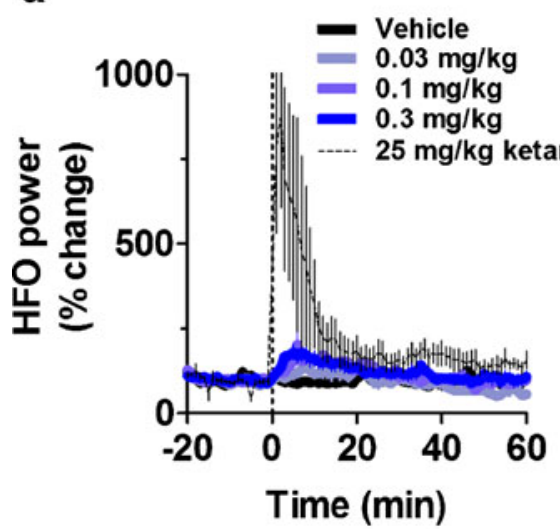

C

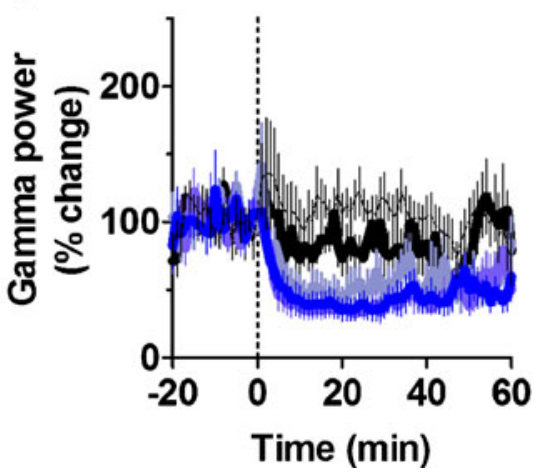

DOI

b

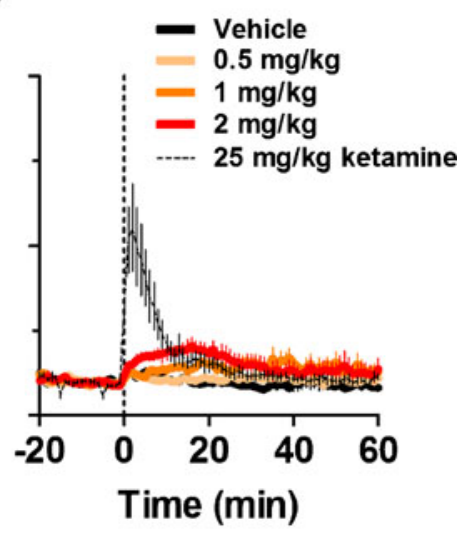

d

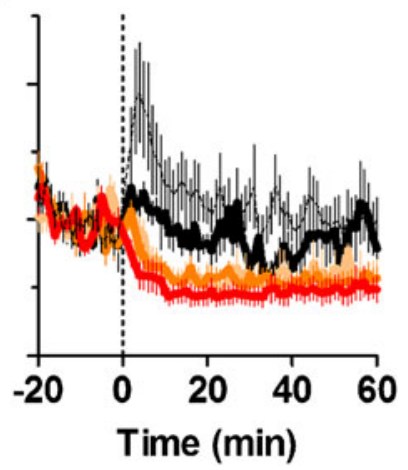


group 1 (LSD group), we observed a long-lasting enhancement of HFO activity after ketamine, different from the rest of the group, and this rat was excluded from the analysis. Time courses of the total power of HFO after ketamine injection for both groups are shown in Fig. 5a, b. Repeated-measures twoway ANOVA for the LSD and DOI groups including their respective ketamine data revealed significant effects of drug (LSD group, $F_{4,25}=4.47, p<0.0073$; DOI group, $F_{4,25}=3.93$, $p=0.0130$ ), time (LSD group, $F_{79,1975}=5.61, p<0.0001$; DOI group, $\left.F_{79,1975}=12.91, p<0.0001\right)$ and interaction (LSD group, $F_{316,1975}=3.18, p<0.0001$; DOI group, $\left.F_{316,1975}=7.15, p<0.0001\right)$. Bonferroni post hoc test revealed that the ketamine-enhanced HFO power was significantly greater than that produced by all doses of LSD $(p<0.001)$ and DOI $(p<0.001)$. Similarly, repeatedmeasures two-way ANOVA for the TCB-2 and CP 809101 groups including their respective ketamine data revealed significant effects of drug $\times$ time interaction (TCB-2 group, $F_{300,1875}=9.98, p<0.0001$; CP 809101 group, $\left.F_{292,1825}=21.36, p<0.0001\right)$. Bonferroni post hoc test revealed that the ketamine-enhanced HFO power was significantly greater than that produced by all doses of TCB-2 $(p<0.001)$ and CP $809101(p<0.001)$.

Time courses of the total power of gamma after ketamine injection for both groups are shown in Fig. 5c, d. Analysis of low gamma power, with the ketamine data included, revealed drug $\times$ time effects for $\operatorname{LSD}\left(F_{316,1975}=1.80, p<0.0001\right)$ and DOI groups $\left(F_{312,1975}=2.60, p<0.0001\right)$. The power of low gamma for all doses of LSD $(p<0.01$, except the lowest dose) and DOI $(p<0.001)$ were significantly lower compared to injection of ketamine. Repeated-measures ANOVA for the TCB-2 and CP 809101 studies also revealed significant drug $\times$ time interactions (TCB-2 group, $F_{300,1875}=$ $2.14, p<0.0001$; CP 809101 group, $F_{292,1825}=2.15, p<0.0001$ ). The power of low gamma for all doses TCB-2 and CP 809101 $(p<0.001)$ were significantly lower compared to injection of ketamine.

\section{Discussion}

Serotonergic hallucinogens increase the power of HFO recorded in the LFPs of the NAc

LSD is a partial agonist at several 5HT receptor subtypes and also possesses activity on other receptor systems (Halberstadt and Geyer 2011; Marona-Lewicka et al. 2009). DOI is more selective than LSD at 5HT2 receptors with higher affinity for $5 \mathrm{HT}_{2 \mathrm{~A}}$ compared to $5 \mathrm{HT}_{2 \mathrm{C}}$ subtypes (ki=0.7 and $2.4 \mathrm{nM}$ for human $5 \mathrm{HT}_{2 \mathrm{~A}}$ and $5 \mathrm{HT}_{2 \mathrm{C}}$ receptors, respectively). In our study, both drugs produced small but significant increases in the power of HFO in the LFPs recorded from NAc. To try and elucidate the receptor mechanism involved in the hallucination-induced increase in HFO power, we post-treated rats with MDL 11939, a selective $5 \mathrm{HT}_{2 \mathrm{~A}}$ receptor antagonist, which fully reversed the DOI-induced increases in HFO power. TCB-2, a potent $5 \mathrm{HT}_{2 \mathrm{~A}}$ receptor agonist, induced a robust increase in the power of $\mathrm{HFO}$, implicating a role for $5 \mathrm{HT}_{2 \mathrm{~A}}$ receptors in the increases of HFO power we observed in the accumbal LFPs. We observed a small but significant increase in HFO power at the highest dose of CP 809101, suggesting that $5 \mathrm{HT}_{2 \mathrm{C}}$ receptors might also be involved in the generation of HFO but we did not see any significant reductions in the power of DOI-induced HFO after administration of SB 242084, a selective $5 \mathrm{HT}_{2 \mathrm{C}}$ antagonist. Together, these findings indicate that $5 \mathrm{HT}_{2 \mathrm{~A}}$ receptors chiefly modulate increases in $\mathrm{HFO}$ power induced by serotonergic hallucinogens.

Here, we focussed on the HFO recorded in LFPs from the NAc as we have observed spontaneous HFO in this region and its enhancement after intraccumbal infusion of MK801 (Hunt et al. 2010). Also, our current source density analyses have demonstrated a localisation of HFO after ketamine in this area (Hunt et al. 2011). Activities in the HFO range have been reported in other brain regions after injection of NMDAR receptor antagonists (Nicolas et al. 2011; Phillips et al. 2012). It would be instructive to determine whether, or not, serotonergic hallucinogens produce similar effects on HFO outside the NAc.

LSD, DOI, and TBC-2 not only increased the power of HFO, but decreased their frequency. We have shown before that NMDAR antagonists increase the frequency of accumbal HFO (Hunt et al. 2006). This shows a qualitative difference between these classes of psychoactive compounds. Moreover, we have shown that antipsychotic drugs, particularly the atypicals, in addition to producing a small increase in HFO power, reduced the frequency of both spontaneous and NMDAR induced HFO in the LFPs recorded from NAc (Olszewski et al. 2012). It should be noted that the reductions in frequency produced by antipsychotics are, in general, much larger than those produced by serotonergic hallucinogens. However, how and why antipsychotic and hallucinatory compounds produce similar changes in HFO power and frequency is at present unclear. The mechanisms that underlie the effects of antipsychotics and serotonergic hallucinogens are almost certainly distinct, since hallucinogen mediated effects on HFO appear to be predominantly $5 \mathrm{HT}_{2 \mathrm{~A}}$ activation dependent, while both clozapine and risperidone are antagonists at this receptor (Meltzer et al. 1999).

Serotonergic hallucinogens decrease gamma power in the LFPs recorded from NAc

Recordings from freely moving rats have shown that, within the striatum, gamma oscillations appear more dominant in 
ventral regions (Berke et al. 2004; Masimore et al. 2005). The gamma band can be divided into two sub-bands, termed low $(\sim 50 \mathrm{~Hz})$ and high $(\sim 80 \mathrm{~Hz})$ gamma (van der Meer et al. 2010). In our study, in the majority of rats, we also observed two discrete bands of gamma activity, corresponding to those reported previously (Berke et al. 2004; Berke 2009; Kalenscher et al. 2010), with the power of low gamma being the more dominant of the two. In the presence of hallucinogens, small bouts of low gamma still occurred but these were far less frequent, compared to vehicle controls, and in many rats we observed almost complete cessation of gamma activity which typically lasted for the entire time course. In this respect, our findings are similar to those of Berke (2009) who demonstrated that systemic injection of amphetamine or apomorphine reduced the power of low gamma in the ventral striatum (see Fig. 3 of Berke (2009) and our study). However, he observed decreased low gamma was also associated with an increase in the power of high gamma. A very recent study examining the effect of methamphetamine on accumbal gamma also demonstrated an increase in the power of high gamma, but reported no significant effects on the power of low gamma (Morra et al. 2012). In contrast to psychostimulants, serotonergic hallucinogens did not increase the absolute power of high gamma in the NAc indicating fundamental differences between these drugs. However, at the highest doses, a band in the high gamma frequency range could be seen in the spectrograms and a corresponding peak in the power spectra. Analysis of the proportion of high gamma in the total gamma range did yield a significant difference for DOI, but not for the LSD group. This indicates that serotonergic hallucinogens have some impact on the high gamma frequency band albeit to a far lesser degree than the low gamma band.

Activation of $5 \mathrm{HT}_{2 \mathrm{~A}}$ or $5 \mathrm{HT}_{2 \mathrm{C}}$ receptors alone do not appear to adequately account for the reduction in gamma observed after serotonergic hallucinogens. Firstly, blockade of $5 \mathrm{HT}_{2 \mathrm{~A}}$ receptors, produced only a short-lasting reversal of low gamma and secondly, the reductions in gamma were not reproduced fully using the selective $5 \mathrm{HT}_{2 \mathrm{~A}}$ agonist TCB-2. However, we should point out that, in our study we found relatively low doses of DOI can produce profound reductions in the power of gamma. Considering that the MDL 11939 studies were carried out in the presence of DOI $2 \mathrm{mg} / \mathrm{kg}$, we cannot exclude the possibility that the short lasting effect was due to excess competition by DOI at the $5 \mathrm{HT}_{2 \mathrm{~A}}$ receptor site, displacing the already bound antagonist.

Several in vivo studies have shown that putative fast spiking interneurons, and to a lesser extent medium spiny neurons, can phase lock to either low or high gamma but not both (Berke 2009; Hernandez and Cheer 2012; Kalenscher et al. 2010; van der Meer and Redish 2009). This indicates that the generation of gamma in the NAc may be caused by distinct networks arising from different afferent input or possibly generated by distinct types of interneuron. Crossstructural synchrony of low gamma in the NAc has been observed in the amygdala (Popescu et al. 2009) and ventral tegmental area (Dzirasa et al. 2011) both of which project to the NAc. Indeed, the changes we recorded in the NAc may be secondary to effects on one or more of the accumbal afferent sites. Behaviourally, changes in the power of low gamma in the striatum has been related to reward-associated tasks (Berke 2009; Hernandez and Cheer 2012; Kalenscher et al. 2010; van der Meer and Redish 2009), movement initiation (Masimore et al. 2005), and anxiety-related behaviours (Dzirasa et al. 2011). Consequently, the reduction in low gamma power produced by serotonergic hallucinogens may impair functional coupling between mesolimbic regions leading to behavioural disturbances.

The mechanism of gamma generation in the NAc is only partially understood and there is much debate about the locality of gamma oscillations in the striatum and the extent to which they reflect truly local activity or volume-conducted currents, such as from the piriform cortex (Berke 2005). While a proportion of low gamma recorded in the NAc may originate from the piriform cortex, findings that the firing of both interneurons and medium spiny neurons can cohere with this oscillation indicates that a proportion of low gamma does represent authentic local processing (Berke 2009; Dzirasa et al. 2011; Hernandez and Cheer 2012; Kalenscher et al. 2010; van der Meer and Redish 2009).

Comparison of the changes in accumbal HFO and gamma with NMDAR antagonists

The most obvious difference between serotonergic hallucinogens and NMDAR antagonist-enhanced HFO is mainly quantitative in nature, with NMDAR antagonists producing much greater increases in power. This was borne out in our current study where, at the end, all rats were injected with ketamine $25 \mathrm{mg} / \mathrm{kg}$ and we observed several fold greater increases in power compared to the hallucinogens (see Fig. 5). The maximal doses of LSD and DOI used in this study were towards the top end of those typically used by other groups (Bishop et al. 2004; Erdtmann-Vourliotis et al. 1999; Gaggi et al. 1997; Nielsen and Scheel-Kruger 1986). Thus, the relatively weaker effect on HFO power, in comparison to NMDAR antagonists, is unlikely to be related to the doses we used. Indeed, at the medium and high doses of LSD and DOI, we observed clear classical behavioural effects such as wet-dog shakes and postural changes, as reported by others (Gaggi et al. 1997). Even at the lowest dose, we found a clear reduction in gamma power (see Figs. 1e and 2e) demonstrating that the low doses of hallucinogens do affect the electrical activity of the NAc, but that 
larger doses are required to influence the power of HFO. Also, the smaller increases in HFO power produced by LSD and DOI cannot be attributed to their partial agonist activities at 5HT receptors, since TCB-2, is a full agonist at $5 \mathrm{HT}_{2 \mathrm{~A}}$ receptors and produced a quantitatively similar increase. Thus, hallucinogens do not merely produce a "weakened" increase in HFO power, but rather modulate HFO in a qualitatively and quantitatively distinct manner. MDL 11939 did not influence the power of spontaneous or MK801-enhanced HFO (unpublished observation) indicating that $5 \mathrm{HT}_{2 \mathrm{~A}}$ receptors do not underlie the generation of HFO per se, but rather mediate increases in power produced by serotonergic hallucinogens.

In freely moving rats, systemic injection of hallucinogens produced a dramatic reduction in the power of low gamma in the NAc, indicating potent effects of these compounds on gamma oscillations. In general, NMDAR antagonists increase the power of gamma in several brain regions, including the hippocampus, cortex and a variety of other areas. A recent study by Nicolas et al. (2011) demonstrated that increases in both low and high gamma occur in several subcortical areas. In contrast in the NAc, a different pattern emerges. We found using bipolar recordings that ketamine produces a small but significant decrease in the power of "broadband" gamma in the NAc, but simultaneously increases the power of gamma in the hippocampus (Hunt et al. 2011). Reductions in gamma power were also found after administration of a moderated dose $0.5 \mathrm{mg} / \mathrm{kg}$ of MK801, which produced a sustained decrease in broadband gamma power in the NAc (Hunt et al. 2010). In the current study, we focussed on low gamma and found it to be relatively unaffected after injection of ketamine.

We summarise this aspect of our study as follows: systemic administration of serotonergic hallucinogens and NMDAR antagonists influence the generation of HFO and gamma in the NAc, but with different orders of potency [changes in HFO power: NMDAR antagonists > hallucinogens, changes in gamma power: hallucinogens $>$ NMDAR antagonists].

\section{Conclusions}

The NAc has long been considered one of the core structures involved in integration of corticolimbic signalling, in part, due to its anatomical location and ability to gate afferent information. These findings add to a growing body of literature suggesting that the NAc is an important target for the actions of psychoactive compounds. Given the importance of fast oscillations in higher cognitive function and binding alterations, these electrophysiological changes may either impose, or reflect, altered information processing in this structure.
Acknowledgments This work was supported by the EU and the European Regional Development Fund (Polish Science Foundation grant MPD/2009/4), Polish Ministry of Science and Higher Education grant no NN303345435 and the Nencki Institute statutory funds. The authors wish to thank Prof. Urszula Sławińska from the Laboratory of Neuromuscular Plasticity for her kind gift of MDL 11939 for the initial pilot studies.

Open Access This article is distributed under the terms of the Creative Commons Attribution License which permits any use, distribution, and reproduction in any medium, provided the original author(s) and the source are credited.

\section{References}

Aghajanian GK, Marek GJ (1999) Serotonin and hallucinogens. Neuropsychopharmacology 21:16S-23S

Appel NM, Mitchell WM, Garlick RK, Glennon RA, Teitler M, De Souza EB (1990) Autoradiographic characterization of (+-)-1(2,5-dimethoxy-4-[125I] iodophenyl)-2-aminopropane ([125I] DOI) binding to 5-HT2 and 5-HT1c receptors in rat brain. J Pharmacol Exp Ther 255:843-857

Berke JD (2005) Participation of striatal neurons in large-scale oscillatory networks. In: Bolam JP, Ingham CA, Magill PJ (eds) The basal ganglia VIII. Springer, New York, pp 25-35

Berke JD (2009) Fast oscillations in cortical-striatal networks switch frequency following rewarding events and stimulant drugs. Eur J Neurosci 30:848-859

Berke JD, Okatan M, Skurski J, Eichenbaum HB (2004) Oscillatory entrainment of striatal neurons in freely moving rats. Neuron 43:883-896

Bishop C, Tessmer JL, Ullrich T, Rice KC, Walker PD (2004) Serotonin 5-HT2A receptors underlie increased motor behaviors induced in dopamine-depleted rats by intrastriatal 5-HT2A/2C agonism. J Pharmacol Exp Ther 310:687-694

Celada P, Puig MV, Diaz-Mataix L, Artigas F (2008) The hallucinogen DOI reduces low-frequency oscillations in rat prefrontal cortex: reversal by antipsychotic drugs. Biol Psychiatry 64:392-400

Dimpfel W, Spuler M, Nichols DE (1989) Hallucinogenic and stimulatory amphetamine derivatives: fingerprinting DOM, DOI, DOB, MDMA, and MBDB by spectral analysis of brain field potentials in the freely moving rat (Tele-Stereo-EEG). Psychopharmacology (Berl) 98:297-303

Dzirasa K, McGarity DL, Bhattacharya A, Kumar S, Takahashi JS, Dunson D, McClung CA, Nicolelis MA (2011) Impaired limbic gamma oscillatory synchrony during anxiety-related behavior in a genetic mouse model of bipolar mania. J Neurosci 31:6449-6456

Erdtmann-Vourliotis M, Mayer P, Riechert U, Hollt V (1999) Acute injection of drugs with low addictive potential (delta(9)-tetrahydrocannabinol, 3,4-methylenedioxymethamphetamine, lysergic acid diamide) causes a much higher c-fos expression in limbic brain areas than highly addicting drugs (cocaine and morphine). Brain Res Mol Brain Res 71:313-324

Finch DM (1996) Neurophysiology of converging synaptic inputs from the rat prefrontal cortex, amygdala, midline thalamus, and hippocampal formation onto single neurons of the caudate/putamen and nucleus accumbens. Hippocampus 6:495512

Gaggi R, Dall'Olio R, Roncada P (1997) Effect of the selective 5-HT receptor agonists 8-OHDPAT and DOI on behavior and brain biogenic amines of rats. Gen Pharmacol 28:583-587 
Halberstadt AL, Geyer MA (2011) Multiple receptors contribute to the behavioral effects of indoleamine hallucinogens. Neuropharmacology 61:364-381

Hernandez G, Cheer JF (2012) Effect of CB1 receptor blockade on food-reinforced responding and associated nucleus accumbens neuronal activity in rats. J Neurosci 32:11467-11477

Hunt MJ, Raynaud B, Garcia R (2006) Ketamine dose-dependently induces high-frequency oscillations in the nucleus accumbens in freely moving rats. Biol Psychiatry 60:1206-1214

Hunt MJ, Garcia R, Large CH, Kasicki S (2008) Modulation of highfrequency oscillations associated with NMDA receptor hypofunction in the rodent nucleus accumbens by lamotrigine. Prog Neuropsychopharmacol Biol Psychiatry 32:1312-1319

Hunt MJ, Falinska M, Kasicki S (2010) Local injection of MK801 modifies oscillatory activity in the nucleus accumbens in awake rats. J Psychopharmacol 24:931-941

Hunt MJ, Falinska M, Leski S, Wojcik DK, Kasicki S (2011) Differential effects produced by ketamine on oscillatory activity recorded in the rat hippocampus, dorsal striatum and nucleus accumbens. J Psychopharmacol 25:808-821

Jentsch JD, Roth RH (1999) The neuropsychopharmacology of phencyclidine: from NMDA receptor hypofunction to the dopamine hypothesis of schizophrenia. Neuropsychopharmacology 20:201225

Johnson MP, Hoffman AJ, Nichols DE, Mathis CA (1987) Binding to the serotonin 5-HT2 receptor by the enantiomers of 125I-DOI. Neuropharmacology 26:1803-1806

Kalenscher T, Lansink CS, Lankelma JV, Pennartz CM (2010) Reward-associated gamma oscillations in ventral striatum are regionally differentiated and modulate local firing activity. $\mathrm{J}$ Neurophysiol 103:1658-1672

Kargieman L, Santana N, Mengod G, Celada P, Artigas F (2007) Antipsychotic drugs reverse the disruption in prefrontal cortex function produced by NMDA receptor blockade with phencyclidine. Proc Natl Acad Sci U S A 104:14843-14848

Krebs-Thomson K, Paulus MP, Geyer MA (1998) Effects of hallucinogens on locomotor and investigatory activity and patterns: influence of 5-HT2A and 5-HT2C receptors. Neuropsychopharmacology $18: 339-351$

Ma J, Leung LS (2000) Relation between hippocampal gamma waves and behavioral disturbances induced by phencyclidine and methamphetamine. Behav Brain Res 111:1-11

Marona-Lewicka D, Chemel BR, Nichols DE (2009) Dopamine D4 receptor involvement in the discriminative stimulus effects in rats of LSD, but not the phenethylamine hallucinogen DOI. Psychopharmacology (Berl) 203:265-277

Masimore B, Schmitzer-Torbert NC, Kakalios J, Redish AD (2005) Transient striatal gamma local field potentials signal movement initiation in rats. Neuroreport 16:2021-2024

McKenna DJ, Nazarali AJ, Hoffman AJ, Nichols DE, Mathis CA, Saavedra JM (1989) Common receptors for hallucinogens in rat brain: a comparative autoradiographic study using [125I]LSD and [125I]DOI, a new psychotomimetic radioligand. Brain Res 476:45-56

Meltzer HY, Park S, Kessler R (1999) Cognition, schizophrenia, and the atypical antipsychotic drugs. Proc Natl Acad Sci USA 96:1359113593

Morra JT, Glick SD, Cheer JF (2012) Cannabinoid receptors mediate methamphetamine induction of high frequency gamma oscillations in the nucleus accumbens. Neuropharmacology 63:565-574

Nichols DE (2004) Hallucinogens. Pharmacol Ther 101:131-181

Nicolas MJ, Lopez-Azcarate J, Valencia M, Alegre M, Perez-Alcazar M, Iriarte J, Artieda J (2011) Ketamine-induced oscillations in the motor circuit of the rat basal ganglia. PLoS One 6:e21814
Nielsen EB, Scheel-Kruger J (1986) Cueing effects of amphetamine and LSD: elicitation by direct microinjection of the drugs into the nucleus accumbens. Eur J Pharmacol 125:85-92

North RA, Uchimura N (1989) 5-Hydroxytryptamine acts at 5-HT2 receptors to decrease potassium conductance in rat nucleus accumbens neurones. J Physiol 417:1-12

O'Donnell P, Grace AA (1995) Synaptic interactions among excitatory afferents to nucleus accumbens neurons: hippocampal gating of prefrontal cortical input. J Neurosci 15:3622-3639

Oades RD, Halliday GM (1987) Ventral tegmental (A10) system: neurobiology. 1. Anatomy and connectivity. Brain Res 434:117-165

Olszewski M, Piasecka J, Goda SA, Kasicki S, Hunt MJ (2012) Antipsychotic compounds differentially modulate high-frequency oscillations in the rat nucleus accumbens: a comparison of firstand second-generation drugs. Int J Neuropsychopharmacol 21:112

Palenicek T, Fujakova M, Brunovsky M, Horacek J, Gorman I, Balikova M, Rambousek L, Syslova K, Kacer P, Zach P, BubenikovaValesova V, Tyls F, Kubesova A, Puskarcikova J, Hoschl C (2013) Behavioral, neurochemical and pharmaco-EEG profiles of the psychedelic drug 4-bromo-2,5-dimethoxyphenethylamine (2C-B) in rats. Psychopharmacology (Berl) 225(1):75-93

Passie T, Halpern JH, Stichtenoth DO, Emrich HM, Hintzen A (2008) The pharmacology of lysergic acid diethylamide: a review. CNS Neurosci Ther 14:295-314

Paxinos G, Watson C (1988) The rat brain in stereotaxic coordinates, 4th edn. New York Acedemic Press, San Diego

Pazos A, Palacios JM (1985) Quantitative autoradiographic mapping of serotonin receptors in the rat brain. I. Serotonin-1 receptors. Brain Res 346:205-230

Pazos A, Cortes R, Palacios JM (1985) Quantitative autoradiographic mapping of serotonin receptors in the rat brain. II. Serotonin-2 receptors. Brain Res 346:231-249

Phillips KG, Cotel MC, McCarthy AP, Edgar DM, Tricklebank M, O’Neill MJ, Jones MW, Wafford KA (2012) Differential effects of NMDA antagonists on high frequency and gamma EEG oscillations in a neurodevelopmental model of schizophrenia. Neuropharmacology 62:1359-1370

Pinault D (2008) $N$-methyl-D-aspartate receptor antagonists ketamine and MK-801 induce wake-related aberrant gamma oscillations in the rat neocortex. Biol Psychiatry 63:730-735

Popescu AT, Popa D, Pare D (2009) Coherent gamma oscillations couple the amygdala and striatum during learning. Nat Neurosci 12:801-807

Robbe D, Montgomery SM, Thome A, Rueda-Orozco PE, McNaughton BL, Buzsaki G (2006) Cannabinoids reveal importance of spike timing coordination in hippocampal function. Nat Neurosci 9:1526-1533

Teitler M, Leonhardt S, Weisberg EL, Hoffman BJ (1990) 4-[125I] iodo-(2,5-dimethoxy)phenylisopropylamine and $[3 \mathrm{H}] \mathrm{ketanserin}$ labeling of 5-hydroxytryptamine2 (5HT2) receptors in mammalian cells transfected with a rat 5HT2 cDNA: evidence for multiple states and not multiple 5HT2 receptor subtypes. Mol Pharmacol 38:594-598

van der Meer MA, Redish AD (2009) Low and high gamma oscillations in rat ventral striatum have distinct relationships to behavior, reward, and spiking activity on a learned spatial decision task. Front Integr Neurosci 3:9

van der Meer MA, Kalenscher T, Lansink CS, Pennartz CM, Berke JD, Redish AD (2010) Integrating early results on ventral striatal gamma oscillations in the rat. Front Neurosci 4:300

Vollenweider FX, Geyer MA (2001) A systems model of altered consciousness: integrating natural and drug-induced psychoses. Brain Res Bull 56:495-507 